International Review of Research in Open and Distributed Learning Volume 17, Number 4

June - 2016

\title{
Instructors' Perceptions of Instructor Presence in Online Learning Environments
}

\author{
Jennifer C. Richardson, Erin Besser, Adrie Koehler, JiEun Lim, and Marquetta Strait \\ Purdue University
}

\begin{abstract}
As online learning continues to grow significantly, various efforts have been explored and implemented in order to improve the instructional experiences of students. Specifically, research indicates that how an instructor establishes his or her presence in an online environment can have important implications for the students' overall learning experience. While instructor presence appears to be an important aspect of online learning, more research is needed to fully understand this construct. The purpose of this study was to consider online instructors' perceptions related to presence, beliefs about actions, and the perceived impact of instructional presence. Using an explanatory multiple-case study approach, this research considered the perspectives of 13 instructors teaching in an online master's program at a large Midwestern public university. Results indicate instructors viewed instructor presence as an important component in online courses but their reasons varied. Furthermore, the instructors discussed a number of communication strategies they used, the importance of using such strategies to connect to students, and the potential impact of these strategies on student participation and learning. Additional themes from the interview data are discussed, and implications for online teaching and learning are suggested.
\end{abstract}

Keywords: online education, Community of Inquiry, instructor presences, instructor perceptions

\section{Background}

As online learning continues to grow significantly, various efforts have been explored and implemented in order to improve the instructional experiences of students (Bangert, 2008; Ertmer \& Koehler, 2015; Garrison, Anderson, \& Archer, 2000; Richardson, Koehler, Besser, Caskurlu, Lim, \& Mueller, 2015). Specifically, research indicates that how an instructor establishes his or her presence in an online environment can have important implications on the students' overall learning experience (Garrison et al., 2000; Richardson \& Swan, 2003; Stone \& Chapman, 2006; Swan, 2002). While instructor presence appears to be an important aspect to consider when designing and facilitating an online course (Richardson et al., 2015), little research focuses on instructors' perceptions of their presence (Stone \& Chapman, 2006) and the specific actions taken to project presence in the online courses they teach. Complicating the construct of instructor presence is the reality that in many instances, online instructors are teaching courses that were designed by someone else (Richardson et al., 2015) which is not a widely discussed approach in 
the Community of Inquiry (CoI) literature. This study examines online instructors' perceptions of presence, beliefs about their actions, and ideas about the perceived importance of their presence. As Allen and Seaman (2013) explain, 62.4\% of higher education institutions indicated they offer complete online programs, and the continued growth in online enrollment is a result of "the transition of institutions with only a few online courses moving to offer fully online programs, and from institutions with online programs expanding their offerings and building their enrollments" (p. 21).

Instructors take on many roles as they interact with students. These interactions are important as they can influence students' participation (Jorge, 2010; Mazzolini \& Maddison, 2007; Swan \& Shih, 2005; Tao, 2009; Tu \& McIsaac, 2002), course and instructor satisfaction (Akyol \& Garrison, 2008; Cobb, 2011; Gunawardena \& Zittle, 1997; Hostetter \& Busch, 2006; Richardson \& Swan, 2003), actual and perceived learning (Hostetter \& Busch, 2013; Joksimović, Gašević, Kovanović, Riecke, \& Hatala, 2015; Kang \& Im, 2013; Picciano, 2002; Richardson \& Swan, 2003; Russo \& Benson, 2005; Wise, Chang, Duffy, \& del Valle, 2004), and even retention rates (Boston, Diaz, Gibson, Ice, Richardson, \& Swan, 2009; Liu, Gomez, \& Yen, 2009; Reio \& Crim, 2013). In addition to facilitating learning (e.g., encouraging students and providing tips, being an active voice in course discourse), the instructor role often includes designing curricular materials, managing the learning process and environment (e.g., providing organization of course activities and content, maintaining the flow of the course), and providing a social presence to overcome a feeling of disconnect or isolation among students (e.g., using greetings, names, humor, and self-disclosure; Dennen, Darabi, \& Smith, 2007; Richardson et al., 2015).

As these aspects of a course can potentially impact learning in many ways, instructor presence is an important construct to consider when designing or facilitating online instructional experiences. Results from a survey investigating perceptions of online communities revealed that students felt instructor presence was an important aspect of online learning, as they wanted available instructors that were willing to provide timely feedback, listen to concerns, and guide them through learning tasks (Vesely, Bloom, \& Sherlock, 2007). Additionally, students ranked instructor modeling as the most important element for online learning and building an online learning community. This research is similar to other findings indicating students appreciate online instructors who are responsive to their needs and provide clear explanations of course requirements (Sheridan \& Kelly, 2010).

Moreover, the unique features of online environments have led to the change and expansion of the instructor role. As described by Richardson and Swan (2003), "the role of the instructor can be altered to become more akin to a facilitator than a lecturer, while the role of student can be altered by allowing them to become active learners" (p. 69). In particular, social and facilitating roles are emphasized in online environments because of the lack of physical interaction and presence. To overcome the geographical barriers associated with learning at a distance, online instructors can actively facilitate discussion and attempt more social interaction with students (Picciano, 2002; Vesely et al., 2007).

As instructors assume various roles in online instructional environments, they establish a presence. Specifically, using the Community of Inquiry (CoI) framework, Richardson et al., (2015), conceptualized instructor presence as occurring at the intersection of teaching presence and social presence. The CoI "theoretical framework represents a process of creating a deep and meaningful (collaborativeconstructivist) learning experience through the development of three interdependent elements-social 
presence, cognitive presence and teaching presence" (Akyol \& Garrison, 2013, p. 85). Teaching presence refers to the instructional methods used to develop and support valuable instructional experiences (e.g., Bangert, 2008; Garrison \& Arbaugh, 2007), while social presence refers to the degree of connectedness to others felt by participants in an online instructional environment, (e.g., Garrison \& Arbaugh, 2007; Swan, Garrison, \& Richardson, 2009). The term "instructor presence" does appear in the literature but commonly refers to teaching presence behaviors. In the case of this research, instructor presence is defined as "the specific actions and behaviors taken by the instructor that projects him/herself as a real person... [and] is more likely to be manifested in the 'live' part of courses-as they are being implemented-as opposed to during the course design process" (Richardson et al., , 2015, p. 259). Instructor presence is a comprehensive concept in that it includes instructional design, instructor roles and styles, and specific behaviors and interactions (Feeler, 2012; Richardson et al., 2015). Gaining a deeper understanding of these areas is especially important as we move from the traditional designer-instructor to a growing pool of non-designer instructors, changing the face of online instructors and how "instructors" have traditionally been discussed in the CoI literature.

While instructor presence appears to be an important aspect of online learning, more research is needed to fully understand this construct (Richardson et al., 2015; Sheridan \& Kelly, 2010; Vesely et al., 2007). This is especially true with an increasing number of non-designer instructors teaching online who may have less input into course design decisions that traditionally impact social and teaching presence. The purpose of this study is to consider online instructors' perceptions related to presence, beliefs about actions, and the perceived impact of instructional presence:

1. How much importance do online instructors place on instructor presence in their courses?

2. How do instructors perceive particular communication strategies as promoting their instructor presence?

3. How do instructors perceive their instructor presence behaviors or strategies as helping them connect with students?

4. How do non-designer instructors perceive the impact of predesigned courses on their instructor presence?

\section{Methodology}

In order to examine instructors' perceptions of instructor presence within online environments, this study used an explanatory multiple-case study approach (Yin, 2014). Explanatory case studies are appropriate for this line of research in that they seek to explain certain phenomena (Denzin \& Lincoln, 2011). Multiple case-studies provide opportunities to examine various similarities and differences between cases, while increasing reliability and rigor (Yin, 2014).

\section{Context and Participants}

In the fall of 2011, an online master's program in Learning Design and Technology (LDT) commenced at a large Midwestern public university. This fully online program enrolls approximately 200 students 
continually with students coming from a variety of backgrounds such as education, business, and healthcare. In the online program, courses are eight weeks in length. Courses are designed by fulltime faculty members but are taught by a number of limited term lecturers (LTLs) as well as the fulltime faculty.

This research is a follow-up investigation to a study conducted by Richardson et al. (2015) that examined the instructor presence behaviors of twelve online instructors. In the initial study, instructor profiles emerged offering insight into ways instructional elements and strategies work together to create optimal online learning experiences. Furthermore, this study also revealed practical ways for instructors to improve their online practices.

In the current study, purposive sampling was used to explore the instructor presence of 13 instructors. Instructors were selected based on the courses they were teaching, designed, or both to ensure varying interests, backgrounds, and experiences were considered. The instructors for these courses included both fulltime university faculty members $(n=4)$ and LTLs $(n=9)$. Of the instructors in our sample all indicated some type of training with the learning platform (BlackBoard) and three indicated some formal training for how to teach online. It should also be noted that several indicated they were the developers of training to teach others to teach online $(n=3)$ and all came from a background in or related to Learning Design and Technology; Table 1 includes further instructor information.

Table 1

Instructor Information

\begin{tabular}{lllll}
\hline Instructor & & $\begin{array}{l}\text { Online } \\
\text { Teaching }\end{array}$ & \\
Pseudonyms & Faculty Status & Experience* & Background & TA \\
\hline Liam & LTL but FT elsewhere & High & K-12 and Higher Ed & No \\
Isabelle & FT & High & K-12 and Higher Ed & Yes \\
Amy & LTL & High & Higher Ed & No \\
Ava & LTL & High & Higher Ed & No \\
Ethan & LTL & Medium & Higher Ed & No \\
Sophia & LTL & Medium & Higher Ed & No \\
Julie & LTL & Medium & Higher Ed & No \\
Daniel & LTL but FT elsewhere & High & Higher Ed & No \\
Olivia & LTL & High & Corporate \& Higher Ed & No \\
Heather & LTL but FT elsewhere & High & K-12 and Higher Ed & Yes \\
Emma & FT & High & K-12 and Higher Ed & Yes \\
Jake & FT & High & Higher Ed & Yes \\
Ryan & FT & High & Higher Ed &
\end{tabular}

Note. ${ }^{*}$ High Experience level indicates 5 years or more experience teaching online or $10+$ courses. LTL =limited term lecturer; FT =full time program faculty.

\section{Data Sources and Collection}


Jacob and Furgerson (2012) suggest first visiting the literature when developing an interview protocol. As noted in the literature review, instructor presence is poorly defined in current research, but appears to be related to an instructor's social presence, immediacy, interactivity, and instructional style (Sheridan \& Kelly, 2010; Stone \& Chapman, 2006). Research shows students perceive different teaching presence factors related to their success (e.g., direct instruction, facilitation, and discourse) or lack of success (e.g., lack of feedback, unclear course communications) in an online course (Kupczynski, Ice, Wiesenmayer, and McCluskey, 2010). At the same time, instructor presence appears to be very personally constructed and connected to instructors' beliefs and instructional style (Stone \& Chapman, 2006). Additionally, previous research has not fully considered instructors' perceptions. As instructor perceptions and beliefs can be a major determinant in their actions and behaviors; gaining this perspective is valid and important. Therefore, questions were developed around these areas to investigate instructors' perceptions of specific actions and behaviors they used and how they may impact how they project themselves to their students. Specifically, interview questions focused on the following areas:

1) the importance the instructor places on instructor presence,

2) specific actions and behaviors the instructor takes to project his or her instructor presence, and

3) the instructor's perception of the outcomes or effects of instructor presence.

Additionally, as there are an increasing number of online instructors teaching courses that were designed by someone else (Richardson et al., 2015), a question focusing on the perceived impact on instructor presence of teaching a course designed by another was also addressed.

During spring 2014, pairs of researchers conducted semi-structured interviews to allow for flexibility in fully exploring instructor presence and perceived student outcomes (See Appendix A). Each interview lasted approximately one hour. As many of the online instructors were not on campus, these interviews were completed using a variety of methods (e.g., phone, Adobe Connect, Skype). Each interview was recorded and transcribed verbatim. In addition to the interview questions, a pre-interview questionnaire was sent to the instructors to collect demographic and background informational data (e.g., years of experience).

\section{Data Analysis}

In order to understand instructors' perceptions of instructor presence, the researchers began by developing individual case studies for each instructor. Codes were developed to specifically capture the nature of instructor perceptions, specific actions and behaviors of instructor presence, student outcomes, and other conditions affecting instructor presence. The coding schema was enhanced through inductive coding and allowing codes to emerge through the analysis process, as well as through the revision of existing codes. The final coding schema consisted of five categories: 1) pre-questions, 2) importance of instructor presence, 3) actions and behaviors taken to project yourself as a real person, 4) course design, and 5) other or miscellaneous. A total of 24 codes were used (seven of these originated from the coding schema developed by Richardson et al., 2015). See Appendix B for the final coding schema. 
In order to gain a greater understanding of instructors' perceptions of instructor presence within online environments, multiple cases were compared for similarities and differences. In accordance with axial coding (Miles, Huberman, \& Saldaña, 2014), the various coded pieces were clustered together into themes, and then finally into overarching dimensions linking back to the CoI framework. Cross-case analysis took on a case-oriented approach where researchers examined each case as its own entity and then explored relationships across various cases.

\section{Reliability and Validity}

Four case study tactics have been established in qualitative research specifically regarding analysis of case study research and validation measures (Yin, 2014). While testing construct validity, a chain of evidence was utilized. Here, procedures and questions were directly linked to citations and research questions. The interview questions were further validated by having experts review them for content appropriateness. Before any interviews were conducted, the questions were piloted on individuals with online teaching experience not participating in this study $(n=4)$. Through this iterative process, face validity and reliability was established.

To test internal validity, two researchers completed each interview. Within the analysis process, two researchers independently coded each interview. Results were them compared and consensus building allowed for 100\% inter-coder agreement for all courses (Creswell, 2014). To test external validity, research questions were matched with the case study research methods (explanatory case-study) and strategies to extend outside of this specific topic and to other relevant theoretical concepts and principles. To ensure reliability, a case study protocol was utilized and procedures were replicated by all members of the research team. While generalizability is not the sole purpose of this qualitative study, testing for reliability and validity strengthens the ability to analytically generalize (Yin, 2014).

\section{Results}

\section{R1. How Much Importance Do Online Instructors Place on Instructor Presence in their Courses?}

When we interviewed the instructors about this topic, they had a lot to share about the concept and how they internalized it, while expressing the level of importance they placed on instructor presence. Every instructor agreed that instructor presence was important, while most felt it was critical or one of the most important aspects of online teaching $(n=11)$. As Julie explained:

I think it's very important. I get the feeling that the students, if they don't feel that the faculty member is real, is responsive to their questions, is a grader that gives feedback-timely and in detail-then they kind of disengage. I think it's human nature.

Two instructors explained how they felt it was very important to the students but not as much to them, as the students felt the need for that connection. Another instructor explained that in some cases it depends on the background or culture of the student, which may lead to different expectations for interacting with the instructor and ultimately students' perceived importance of instructor presence. 
In their descriptions of instructor presence, a number of motives for the importance of instructor presence were shared, including why they felt instructor presence was important. For example, a number of the faculty indicated that they believed students viewed them as someone who is interested in them $(n=8)$, many talked about the importance of letting students know he or she cares about them $(n=7)$, and at least two instructors discussed the need for students to see them as an expert. Similarly, Daniel discussed what he perceived as a need for balance between professionalism and personalizing while meeting students' needs:

I think that you can be real and keep it formal. I like to think of it as keeping it professional. So, whether you're formal or informal, I think that, in my mind, I think we need to be professional.

An interesting theme that evolved from several of the interviews was the idea that while the instructors felt they presented themselves as real people that was just a side benefit of showing students that they care and are there for them.

Finally, when reviewing the interviews and the instructors' perceptions of the importance of instructor presence, interestingly, only four instructors initially mentioned aspects that were closely tied to behaviors typically associated with teaching presence (e.g., course organization, clarification of instructions, tips on how to do well in the course). All others focused on social presence aspects. However, as the interviews progressed, many examples were discussed, illustrating how instructor presence actions and behaviors were deeply rooted in activities traditionally associated with teaching presence.

\section{R2. How Do Instructors Perceive Particular Communication Strategies Taken by Them as Promoting their Instructor Presence?}

Several themes emerged in relation to the instructors' communication strategies. Based on prior literature, many of these themes were expected. However, many approaches were unexpected.

Setting the tone. Setting a friendly, perhaps approachable tone, especially through the use of announcements and course biographies was mentioned frequently $(n=10)$. Prompt replies to students were also discussed by a number of the instructors $(n=6)$, as was making the materials and content relatable to the students and to the real world $(n=3)$. Additionally, a few instructors talked about their communication styles. For example, Daniel discussed tailoring communication to student comfort levels.

Well, I tell people that they can call me whatever they want-they can use my first name... But, in some cultures, they don't want to do that... So, I say that's fine. For example, they want to keep it more formal.

Other instructors talked about their philosophy of communication, such as the idea of reciprocal communication $(n=5)$ and modeling what is expected $(n=2)$.

There is a lot of modeling that goes on especially at the beginning. Meaning that, I respond a lot in opening discussions and the reason is because it sets the tone. The students take over after that. If you sit back in those first two discussions, that also sets the tone, and you are struggling from then 
on. You are wondering later on why they aren't responding, and they are just following what you did. (Ryan)

Taking the online environment into consideration. Several instructors discussed intentionally tailoring their communication style for an online environment. For example, Emma discussed how she approaches communication for the online environment:

I guess always in my head I'm thinking 'what would this be like in a face-to-face class' and 'how do I run a discussion in a face-to-face class.' You call people by name and you smile a lot. I do use emoticons and stuff like that. At the beginning, I thought, I'm just not going to do that. It's so silly... but I do it because I think it does add. It helps with the meaning because if you are trying to use humor, they might take it the wrong way if you don't put your little smiley face in there.

Similarly, Olivia talked about being aware of simple language techniques taken for granted when posted to an online environment. For example, she felt addressing students as learners is important.

I think that students put you into a subservient position. Students put you into a waiting position, a holding position for some teacher to then engage with the student. So, I look at them as learners because that to me empowers them much more to be responsible for their learning because they are the learners, and I am the facilitator, the instructor along the way.

Sharing as a communication strategy. Instructors saw sharing information as a key communication strategy. Many instructors discussed the importance of introductions in the class $(n=10)$, either through the class biographies including pictures or through a video they created to share their background, personal information, or general thoughts on the course. While communication and sharing strategies may change or evolve over the duration of a course, the introductions were pivotal for the sharing of self as an individual.

The instructors' stances on sharing personal information, a central step to allow students to view them as a real person, seemed to fall within two categories: (a) sharing just enough to let students know he or she is an expert or (b) showing a balance between personal and professional sharing by posting stories from both areas and using small talk as a communication strategy.

During interviews, the instructors in category one $(n=6)$ indicated that they don't share "too much" about their personal lives but will share information related to professional background, experiences or both. This doesn't mean in all cases this sharing was done purposefully or even that it wouldn't change given the right circumstances. One instructor explained this circumstantial sharing:

Sometimes when the students come to my office hours and ask me individual personal questions, then I could open myself a little bit. But other than that case, I think I remain more professional, especially during the class announcements or things like that. (Sophia)

Several also discussed sharing their experiences as learners in this discipline: 
So, I think just let them know that you probably went through what they are going through and sharing stories from what I was taught. I would tell them how [professor's name] had us memorize the flowchart for that concept and that we were brought into his office to be tested orally. That was a lot of pressure. Things like that. (Ethan)

Category two instructors $(n=7)$ thought a balance between personal and professional sharing was best. The instructors in this category explained that they shared personal experiences as they related to the content but also used "small talk" to help learners feel more connected to them and to the program. This included campus trivia and facts or commenting on current events and sports. Perhaps, this category is best summarized by Daniel. He explained that relating to his students is very important and that in order to achieve this goal, he uses self-disclosure to share his experiences. First, he understands that many of the students are new to the content that is being covered and provides reassurance through stories of his confusion when he was first learning the content. At the same time, he shares professional experiences with students so that they can see that working on similar projects in real life is messy and challenging. He does share personal information if he believes it will help him connect with his students and illustrate an example. His rule of thumb is to never share information that students would find offensive or "his wife or mother would be embarrassed by." In his view, staying professional at all times is important.

Feedback as a communication strategy. One theme, emerging unexpectedly, was that the instructors viewed their feedback to students as a communication strategy. An important category was the type of feedback provided to learners, and almost all instructors touched upon this in one way or another. Many talked of the need to provide more than a grade in order to let learners know where they had room for improvement. Several mentioned the extensive feedback provided for formal assignments $(n=5)$, including using track changes and comments in word processing documents or even marking a paper "old school" and then scanning it back to learners. For example, Ethan explained using his feedback as a form of communication:

I think grading is one of the big forms of communication. I make sure they get it fast. If they really messed something up, I give them the chance to do it over, and resubmit it to me. So, I think that makes them feel better too and that way it is true communication-they can say is this better if we do this and they do it over. It's extra work for them, but I think it helps because they are learning.

Additionally, seven instructors discussed the importance of providing positive or encouraging comments. As one instructor explained, "When they turn in their project and I mark it up, I try to point out not only weaknesses, but also things that are positive." Olivia explained her perspective on this:

So, if I'm giving feedback on an academic thing, then, it's going to be academic feedback. If I feel that they are not engaged enough, I will say that-so, it's all in how you say it. I don't want to scold them. These are adults. I want to encourage them by saying, 'I hope I see more engagement from you next week.'

Similarly, as these instructors are working with adult learners, some discussed the importance of using "gentle" language when providing assignment feedback and posting on discussion boards to avoid the "scolding effect." As Emma explained, you can include comments such as "That's really interesting, what 
makes you think this?" "Have you thought about this?" and the use of gentle expressions (e.g., I wonder) rather than direct expressions (e.g., I disagree).

Providing feedback within the discussion threads was another theme that emerged. The instructors viewed their role in the discussions as a means to communicate or to model their own teaching styles. For example, several instructors expressed the importance of being a facilitator versus direct respondent in the discussions $(n=6)$ and using less formal or direct feedback when posting in the discussion boards $(n=5)$. Additionally, instructors discussed the need for modeling productive discourse in discussions $(n=2)$, the use of announcements or discussion summaries to provide general feedback on discussions $(n=4)$, and redirecting discussions that were off track $(n=4)$.

\section{R3. How do instructors perceive their instructor presence behaviors or strategies as helping them connect to students?}

From examining the interview responses, instructors perceived that their presence potentially helps them connect with students by influencing participation, learning, and interactions and the climate of the online learning environment.

Connecting with students: Impacting participation, learning, and interaction. About half of the instructors felt that their presence was most important for specific types of learners. First, some instructors $(n=4)$ shared that instructor presence carried more weight for students that were "at-risk," struggling, or facing a specific issue. Isabelle explained her rationale for this standpoint:

I try to make myself be more available and be more like a real person-the students if they have a really hard time with something and if they are in a difficult situation, they will come to me and ask for help. Therefore, I feel like I have had students who had a lot of 'risk factors' who were able to complete and succeed in the courses that they take with me.

Beyond supporting students that are struggling, Mason felt that his presence was important for students who value a connection with their instructor:

I think it impacts some of the students-again, if that is a need they have. I know for myself, I am more introverted. So, it is not something I am looking for. For myself as a student in that situation, I don't really think it would have impact for me. But, there are students who if they don't feel that connection, they don't feel at ease, and that can negatively impact their learning.

Instructors appeared to be less certain about the effect of instructor presence on student learning. Daniel and Isabelle voiced similar roles for instructor presence in impacting learning. While both thought their presence could be influential, they felt this was in a more indirect way:

It's [instructor presence] just like motivation. You can have motivating and engaging instruction. Is it going to enhance the learning? Not directly. It will help people persist with practice or persist with the course. So, I think this helps people want to come to class or want to interact with me, but the bottom line, those in and of themselves, I don't think have much instructional power to be honest. (Daniel) 
In other cases, instructors seemed less certain as to whether their presence impacted learning, but were hopeful. While Emma recognized that her feedback could be very helpful for students, she shared, "Sometimes, I wonder if the students are really reading them [feedback comments]. Not everyone appreciates it or takes the time to really absorb what you are trying to show them." Ava and Sophia expressed uncertainty when asked about how their presence might impact student learning. Julie also shared a story of how she felt her presence helped a group project:

I just related about the opportunity to give me a phone call: I think the individual who had felt that was a need, and felt that things calmed down. I think she was able to adapt a little more of a peacemaker role. And because then the group came together, they were able to have a more positive learning experience. And, in the end, they put together a very excellent project. So, hopefully, that meant they learned something.

While many of the instructors felt uncertain about the specific impact of their presence on learning, most felt more certain that their actions and behaviors, or lack thereof, did influence how students interacted and participated in the course. For instance, three instructors felt that the specific techniques that they modeled in their courses led to students adopting similar behaviors.

Finally, in two instances, instructors discussed the negative impact resulting from a lack of instructor presence. During the teaching of one course, Amy shared that her discussion board participation was not very active:

I was having a little bit of problems with my schedule and was not as involved on the discussion board as I would have liked and as the university would have liked me to be. I know that I would have or could have negatively affected learning.

Ryan has observed similar situations in online courses. He explained that when instructors fail to be actively involved with a course early, then they are setting themselves up for problems and has seen students become detached from a lack of presence.

Teaching in an online learning environment. Considering the specific impact of their actions, nearly half of the instructors shared that they believed their presence specifically influenced the online learning environment for the course they were teaching $(n=6)$. In other words, in order to connect with the students in an online environment, they took specific actions.

For example, Isabelle explained her approach:

In the public space, I try to be more encouraging. That translates into the class being much more harmonious. I really learned that, that's very important to me-so, I don't have to take care of student conflicts issues and things like that. I really make sure that I make a big point that I really want this to be positive and harmonious experience.... And, it helps the students be more professional and have a better attitude about learning and their colleagues.

Similarly, other instructors discussed actions that also related to their communication strategies and styles. For example, Amy shared, "So I think because I'm more casual in how I communicate [online] and think 
they are more willing to say hey I'm having this issue and do not feel that they have to be as formal with me."

\section{R4. How Do Non-Designer Instructors Perceive the Impact of Predesigned Courses on Their Instructor Presence?}

All but one of the interviewed instructors expressed that they did not feel teaching a course designed by someone else impacted their presence. Daniel explained why course design did not impact his presence:

I mean any courses that have been designed for me, I'm going to twist it. I'm going to tweak it so that it works. Give me a pre-designed course, and I mean that's the personalization that any faculty will take on a course.

However, some instructors felt restricted or frustrated with teaching a course they did not design. For instance, Olivia expressed that while teaching a course she did not design was frustrating, it was even her job to own mistakes of the course designer: "If they [students] think that is my fault, I'm going to take it as my fault. I'm going to say, 'there is an issue there, let me fix it.' I'm not going to say, 'Oh my God, the person who designed this is terrible." Mason expressed similar ideas:

Since it's not my course, I am little more restricted to what I can do in it... I wouldn't say that is impacting how I am trying to be personable with them or have a presence with them. The only way it might be impacting things... The structure is kind of already set. So, any flexibility in terms of customization or for the students or things like that is a little bit predetermined.

Four of the instructors interviewed were course designers. Only in one instance did the course designer (Isabelle) share that building in opportunities for instructor presence was done intentionally. "Well I make sure that they [instructors] have the introduction posts, and also, I told my LTLs that work with me on [this course] that they can create personal videos on their own." For the other designers, while instructor presence was not a design consideration, they felt that their courses still provided instructors with the flexibility to establish a presence. Emma explained many opportunities existed for instructors to establish their presence when teaching the course she designed.

Setting up that intro blog for everyone to do. I really stress the importance of being present in the discussion... The opportunities are there. The course was built for the instructor to be an important part of it, and again, I didn't think of it in terms of presence but in terms of facilitating the discussion that took place.

\section{Discussion}

When asked about the importance of instructor presence, several instructors used the concept of "being real" as a way to connect their own understandings to the concept. Moreover, instructors didn't initially perceive their teaching presence actions to be a strong part of their instructor presence. Instead, most viewed their social presence actions as synonymous with instructor presence, at least initially. Instructors may be unaware of the potential impact of teaching presence actions on the overall presence they are 
demonstrating in the course. Considering teaching presence strategies and reflecting on the impact of all behaviors may be helpful for instructors to realize the weight of their actions.

All instructors indicated that instructor presence was indeed important to the success of students in an online course but their reasons varied. This coincides with and builds off previous literature (Garrison et al., 2000; Richardson \& Swan, 2003; Stone \& Chapman, 2006; Swan, 2002). The instructors interviewed in this investigation underscored the important role instructor presence plays in connecting with students through being approachable, showing them concern for their success, and demonstrating expertise. Instructors agree that participation and engagement is key even when the instructor personally doesn't perceive the need for such connections.

The use of particular communication strategies taken by the instructors to establish their instructor presence varied. Most discussed the need for setting the tone. In this case, the tone generally referred to modeling expected behaviors in discussions and making themselves approachable as instructors. Only a few specifically expressed consideration for the online environment and how they tailored communications for this type of setting. Perhaps no strategy varied as much as that of sharing personal information. We categorized these into two levels-those that are willing to share considerably and those that are hesitant to share anything personal. The best take away from this theme is the idea of balance: Instructors should share a balance of both personal and professional information in order to create an instructional presence that helps students see them as having a life but willing to help guide. In part, this is done by sharing stories related to content. This may not be something that comes naturally to new instructors. Therefore, providing novice instructors with examples of professionalism and balance as well as appropriate conduct in educational settings would be a helpful approach.

The use of feedback as a communication strategy was unexpected although practical. In an online environment, feedback is a large portion of the communication between an instructor and students. According to previous research, feedback in online courses may be even more important than in face-toface classes because of the potential geographical disconnect, and at the same time, lack of feedback is often cited as a reason for lower student retention (Dennen et al., 2007; Richardson et al., 2015). The instructors in this study provided techniques for sharing feedback effectively including the use of positive comments, gentle language, and redirection of student work and discussions. The use of feedback as a communication strategy is one area that new instructors could also use direction. For example, there may be an assumption that instructors know how to give good feedback because they are instructors. Additionally, it is worthwhile for veteran online instructors to examine their feedback techniques and consider areas for improvement. Within the online environment, feedback becomes an important form of communication, and guidelines could be developed for instructors.

This study also determined that instructor presence is personal-both for the instructors and the students. Instructors view different actions, behaviors, and tools as being very important for establishing presence and connecting with students (Stone \& Chapman, 2006). The instructors in this study also shared how they felt their instructor presence impacts not only connections to students but potentially student success within a course. This is similar to previous findings. For example, Vesely et al. (2007) found that students most wanted available instructors that were willing to provide timely feedback, listen to concerns, and guide them. Instructors in this study believed that their presence is certainly impactful to students, and 
in some instructors' opinions, may be more influential with certain types of learners, just as a lack of instructor presence could negatively impact students' success. At the same time, instructors did not agree on just how impactful their presence is in an online course-expressing varying perceptions of the weight their influence carried. Specifically, instructors' views were more uncertain on the impact of instructor presence on learning compared to the impact of instructor presence on connecting with students. That is, instructors felt more confident that their specific actions and behaviors impacted the connections they made with students.

Finally, the results of this study have conceptual implications and implications for course design. As the number of online course offerings continues to increase, likely the number of non-designer instructors will also increase. While none of the non-designer instructors in our study $(n=9)$ believed that teaching a course designed by another impacted their instructor presence, they did share feelings of being restricted or even frustrated from not having complete control. Several shared how they altered instructor presence behaviors and actions in courses they did not design. When the designers were asked about building opportunities for instructor presence into their courses only one indicated this was done purposefully. The other course designers indicated that while it was not purposeful, in their design, flexibility existed for instructors to promote their own instructor presence. This helps inform course designers about the need to build in flexibility to allow non-designers to incorporate their own techniques for projecting their presence. Meanwhile, conceptually, the context of non-designer instructors presents another opportunity through which to examine the CoI model.

\section{Conclusion}

The concept of instructor presence provides a way for practitioners and researchers to talk about the role of the non-designer instructor through the lens of the Community of Inquiry framework. With the continued increase in online course delivery we are seeing the changing face of the online instructor as more programs are hiring adjuncts and limited term lectures to teach courses designed by another. Through research we can better hope to fully realize the role of the instructor in the implementation phase of online teaching and learning. As Garrison and Arbaugh contend (2007), while the nature of the relationships between the elements has been established, there is still much to be learned as contexts change including disciplines, course delivery, and characteristics of the learners, instructors, or both.

Limitations for this study include participants from a single program. Additionally, the program being examined is a graduate level master's program and therefore may not be as applicable to undergraduate or professional programs.

The instructors in this study felt that instructor presence is an important aspect of online teaching and learning and shared a variety of communication strategies to promote this presence, indicating that learning more about this construct is worthwhile. More research is necessary to determine which actions, behaviors, and tools are most influential on the success of students in online courses in terms of participation (Jorge, 2010; Mazzolini \& Maddison, 2007; Swan \& Shih, 2005; Tao, 2009; Tu \& McIsaac, 2002) and actual and perceived learning (Hostetter \& Busch, 2013; Joksimović et al., 2015; Kang \& Im, 2013; Picciano, 2002; Richardson \& Swan, 2003; Russo \& Benson, 2005; Wise et al., 2004). Along these lines it would seem that research into instructors' pedagogical philosophies and how those philosophies relate to their conception 
of instructor presence and use of particular strategies could be fruitful. Additionally, a strand of research focusing on students' perceptions about instructor presence and related strategies could provide further insights for instructors and designers. Finally, as we commented in our previous study (Richardson et al., 2015), our understanding will continue to evolve over time as will the concept of instructor presence and expectations associated with that concept.

\section{References}

Akyol, Z., \& Garrison, D. R. (2008). The development of a community of inquiry over time in an online course: Understanding the progression and integration of social, cognitive and teaching presence. Journal of Asynchronous Learning Networks, 12(3-4), 3-22. doi: 10.1111/j.14678535.2009.01029.x

Akyol, Z., \& Garrison, D. R. (2013). Toward the development of a metacognition construct for communities of inquiry. Internet and Higher Education, 17, 84-89.

doi:10.1016/j.iheduc.2012.11.005

Allen, I. E., \& Seaman, J. (2013). Changing course: Ten years of tracking online education in the United States. Newburyport, MA: Sloan Consortium.

Bangert, A. (2008). The influence of social presence and teaching presence on the quality of online critical inquiry. Journal of Computing in Higher Education, 2O(1), 34-61. doi: 10.1007/BFo3033431

Cobb, S. C. (2011). Social presence, satisfaction, and perceived learning of RN-to-BSN students in webbased nursing courses. Nursing Education Perspectives, 32(2), 115-119. doi:10.5480/1536-502632.2.115

Creswell, J. W. (2014). Research design: Qualitative, quantitative, and mixed methods approaches (4th ed.). Thousand Oaks, CA: Sage.

Dennen, V. P., Darabi, A. A., \& Smith, L. J. (2007). Instructor-learner interaction in online courses: The relative perceived importance of particular instructor actions on performance and satisfaction. Distance Education, 28(1), 65-79. doi:10.1080/01587910701305319

Denzin, N. K., \& Lincoln, Y. S. (2011). The SAGE handbook of qualitative research (4th ed.). Thousand Oaks, CA: Sage.

Ertmer, P. A., \& Koehler, A. A. (2015). Facilitated versus non-facilitated online case discussions: comparing differences in problem space coverage. Journal of Computing in Higher Education. doi: $10.1007 /$ s12528-015-9094-5.

Feeler, W. (2012). Being there: A grounded-theory study of student perceptions of instructor presence in online classes (Doctoral dissertation). Retrieved from ProQuest LLC. (UMI No. 1266830430) 
Garrison, D. R., Anderson, T., \& Archer, W. (2000). Critical inquiry in a text-based environment: Computer conferencing in higher education. The Internet and Higher Education, 2(2), 87-105. doi:10.1016/s1096-7516(oo)ooo16-6

Garrison, D. R., \& Arbaugh, J. B. (2007). Researching the community of inquiry framework: Review, issues, and future directions. The Internet and Higher Education, 1O(3), 157-172. doi:10.1016/j.iheduc.2007.04.001

Gunawardena, C. N. \& Zittle, F. J. (1997). Social presence as a predictor of satisfaction within a computermediated conferencing environment. The American Journal of Distance Education, 11(3), 8-26. doi:10.1080/08923649709526970

Hostetter, C., \& Busch, M. (2006). Measuring up online: The relationship between social presence and student learning satisfaction. Journal of Scholarship of Teaching and Learning, 6(2), 1-12.

Hostetter, C., \& Busch, M. (2013). Community matters: Social presence and learning outcomes. Journal of the Scholarship of Teaching and Learning, 13(1), 77-86.

Jacob, S. A., \& Furgerson, S. P. (2012). Writing interview protocols and conducting interviews: Tips for students new to the field of qualitative research. Qualitative Report, 17(42).

Joksimović, S., Gašević, D., Kovanović, V., Riecke, B. E., \& Hatala, M. (2015). Social presence in online discussions as a process predictor of academic performance. Journal of Computer Assisted Learning, 31(6), 638-654. doi:10.1111/jcal.12107

Jorge, I. (2010). Social presence and cognitive presence in an online training program for teachers of Portuguese: Relation and methodological issues. In IODL and ICEM 2010 joint conference and media days (pp. 427-435). Eskisehir, Turkey: Publisher.

Kang, M., \& Im, T. (2013). Factors of learner-instructor interaction which predict perceived learning outcomes in online learning environment. Journal of Computer Assisted Learning, 29(3), 292301. doi:10.1111/jcal.12005

Kupczynski, L., Ice, P., Weisenmayer, R., \& McCluskey, F. (2010). Student perceptions of the relationship between indicators of teaching presence and success in online courses. Journal of Interactive Online Learning, 9(1), 23-43. doi:10.5210/fm.v13i11.2260

Liu, S. Y., Gomez, J., \& Yen, C.-J. (2009). Community college online course retention and final grade: Predictability of social presence. Journal of Interactive Online Learning, 8(2), 165-182.

Mazzolini, M., \& Maddison, S. (2007). When to jump in: The role of the instructor in online discussion forums. Computers \& Education, 49(2), 193-213. doi:10.1016/j.compedu.2005.06.011

Miles, M. B., Huberman, A. M., \& Saldaña, J. (2014). Qualitative data analysis: A methods sourcebook. Washington, DC: Sage. 
Picciano, A. G. (2002). Beyond student perceptions: Issues of interaction, presence, and performance in an online course. Journal of Asynchronous Learning Networks, 6(1), 21-40. doi:10.1.1.98.6506

Reio, T. G., \& Crim, S. J. (2013). Social presence and student satisfaction as predictors of online enrollment intent. American Journal of Distance Education, 27(2), 122-133. doi: 10.1080/o8923647.2013.775801

Richardson, J.C., Koehler, A., Besser, E., Caskurlu, S. Lim, J., \& Mueller, C. (2015). Conceptualizing and investigating instructor presence in online learning environments. International Review of Research in Open and Distributed Learning, 16(3), 256-297.

Richardson, J. C., \& Swan, K.P. (2003). An examination of social presence in online courses in relation to student's perceived learning and satisfaction. Journal of Asynchronous Learning, 7(1).

Russo, T., \& Benson, S. (2005). Learning with invisible others: Perceptions of online presence and their relationship to cognitive and affective learning. Educational Technology \& Society, 8(1), 54-62.

Sheridan, K., \& Kelly, M. A. (2010). The indicators of instructor presence that are important to students in online courses. MERLOT Journal of Online Learning and Teaching, 6(4), 767-779.

Stone, S. J., \& Chapman, D. D. (2006). Instructor presence in the online classroom. Online Submission, 1370-1377.

Swan, K. (2002). Building learning communities in online courses: The importance of interaction. Education, Communication \& Information, 2(1), 23-49. doi:10.1080/1463631022000005016

Swan, K., \& Shih, L. F. (2005). On the nature and development of social presence in online course discussions. Journal of Asynchronous Learning Networks, 9(3), 115-136. doi:10.1.1.102.5653

Tao, Y. (2009). The relationship between motivation and online social presence in an online class (Doctoral dissertation). Retrieved from ProQuest Dissertations and Theses database. (Order No. 3357909).

Tu, C. H., \& McIsaac, M. (2002). The relationship of social presence and interaction in online classes. The American Journal of Distance Education, 16(3), 131-150. doi:10.1207/S15389286AJDE1603_2

Vesely, P., Bloom, L., \& Sherlock, J. (2007). Key elements of building online community: Comparing faculty and student perceptions. MERLOT Journal of Online Learning and Teaching, 3(3), 234246.

Wise, A., Chang, J., Duffy, T., \& Del Valle, R. (2004). The effects of teacher social presence on student satisfaction, engagement, and learning. Journal of Educational Computing Research, 31(3), 247271. doi:10.219o/volb-1m37-rnr8-y2u1

Yin, R. K. (2014). Case study research: Design and methods (5th ed.). Los Angeles: Sage. 


\section{Appendix A}

\section{Interview Protocol}

For the purpose of our study, instructor presence is defined as: The specific actions and behaviors taken by the instructor that projects him- or herself as a real person.

\section{Questions}

1. How much importance do you place on projecting yourself as a real person in the online courses you teach?

a. How much importance do you think students place on seeing you as a real person?

Actions and Behaviors Taken to Project Yourself as a Real Person:

2. In thinking about EDCI , what actions, behaviors, or strategies do you use to project yourself as a real person? In general, how do you project yourself as a real person to your students?

3. Are there specific tools (either within or outside of Blackboard) you use to enhance how students see/view you as a real person?

i. How do you use announcements?

ii. How do you use blogs?

iii. How do you use e-mail with your students (frequency, purposes)?

iv. Any other tools?

4. Are there specific instructional or social/personal techniques you use to enhance how you help your students see you as a real person?

i. Communication strategies (e.g., frequency, personal details)?

1. In regards to personal information, how do you decide what information to share? How much personal information do you share? 
ii. What strategies do you use for providing feedback on course activities (e.g., assignments, discussion forums, wikis, etc.)?

1. What do you consider?

2. How do you determine language and format?

3. Do you provide personalization or encouragement?

iii. Any other instructional or personal techniques you use to help students see you as a real person?

5. You are teaching a course you didn't design does this affect how you project yourself as a real person? Why or why not? (only for non-course builders)

6. You've shared many ways that you project yourself as a real person. So thinking of these, could you speak a little about how you've seen some of your strategies or actions work with your students. Specifically, how do you think the strategies you use help you connect with the students?

i. Is there any relationship?

ii. Do you think these strategies impact student learning? If so, how?

iii. Do they affect how the students are projecting themselves?

iv. Are there specific behaviors or actions you take to increase how students project themselves? If so, what?

a. Anything else you have noticed?

7. What types of strategies or actions do you think are most important to students when trying to establish yourself as a real person? 


\section{Appendix B}

\section{Coding Schema}

Table B1

Instructor Perceptions of IP Coding Schema

\begin{tabular}{lll}
\hline Category & Code & Description \\
\hline Prequestions & Pre & Background and previous instructional experience \\
Importance of Instructor & Importance_self & Indicating how important it is to project yourself as \\
Presence & Importance of IP to students & The importance students place on seeing an instructor \\
& & as a real person \\
Actions and Behaviors Taken & ABS_General & The actions and behaviors one uses to project \\
to Project Yourself as a Real & & themselves as real \\
Person & ABS_Tools & Types of mediums one uses to connect with students.
\end{tabular}


ABS_Strategies_Sharing

ABS_Strategies_Feedback

ABS_Strategies_Other

ABS_Over Semester

ABS_Nondesigner

ABS_Student Observations

ABS Connect with Students

ABS_Connect with

Students_Learning

ABS_Connect with Students_Stu

projection
The act of providing information, albeit personal or professional.

Providing constructive response to one's work or participation within a certain time frame.

Other unmentioned methods that help increase instructor presence.

Changes that instructors make in their delivery of provided tools throughout a course.

The perspective of an instructor that has not designed the course for which they are teaching.

The observations of how these methodologies have been effective in accordance to students' behaviors. The impact of the instructor's strategies and their relationship with their students.

The impact of the instructor's strategies and how it correlates with the students' learning.

The impact of the instructor's strategies and how it correlates with the students' comprehension and application of the content. 


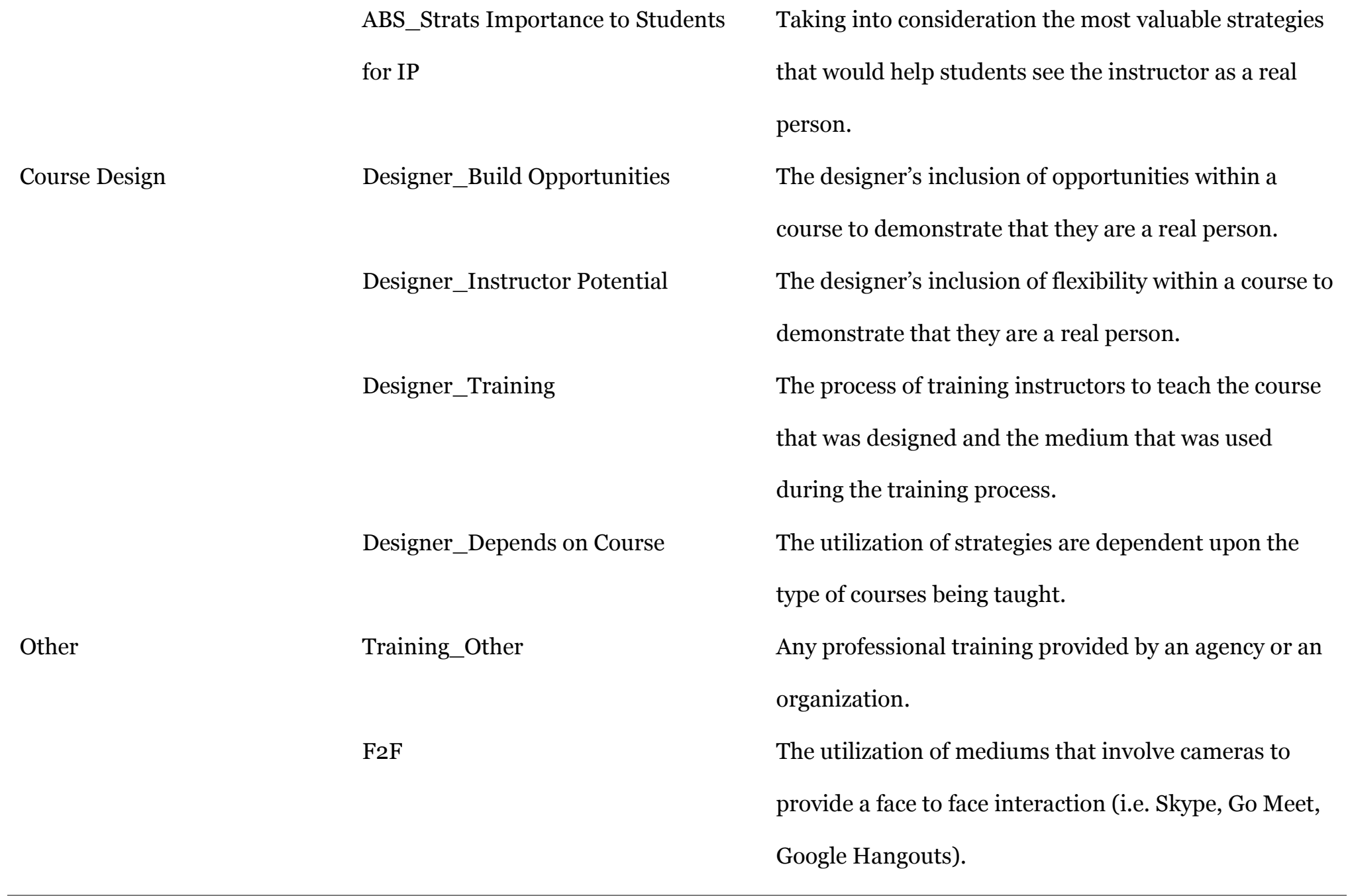

Athabasca

University 
(c) $\underset{\mathrm{EY}}{\mathrm{EY}}$ 